\title{
Simultaneous coronary artery disease and achalasia surgery: A novel approach
}

\author{
Eşzamanlı koroner arter hastalığı ve akalazya cerrahisi: Yeni bir yaklaşım

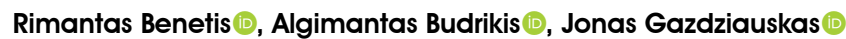 \\ Department of Thoracic and Vascular Surgery, Lithuanian University of Health Sciences, Clinic of Cardiac, Kaunas, Lithuania
}

\begin{abstract}
A 69-year-old female patient presented to cardiac surgery department with unstable angina due to severe coronary artery disease. Coronary artery bypass grafting was indicated; however, the patient's symptoms of achalasia, previously treated by the pneumatic dilatation, exacerbated. Subsequently, the patient underwent simultaneous surgery. After sternotomy, on cardiopulmonary bypass, esophagus was exposed and Heller myotomy was performed. Following cardioplegia, coronary artery bypass grafting was completed. The postoperative course was uneventful, and the patient was discharged on postoperative Day 9. In conclusion, this novel surgical technique can be effectively used in such cases.
\end{abstract}

Keywords: Coronary artery bypass grafting, esophageal achalasia, Heller myotomy.

Coronary artery bypass grafting (CABG) is a standard method for treating advanced ischemic heart disease. ${ }^{[1]}$ The success of cardiac surgery depends not only on the heart's function before the operation, but also on concomitant pathology. ${ }^{[2]}$ In some cases, symptomatic achalasia may present with ischemic heart disease.

Treatment options for severe achalasia include pneumatic dilation, peroral endoscopic myotomy (POEM), and Heller myotomy that are worldwide adopted with a high success rate. ${ }^{[3,4]}$ However, manipulations on the esophagus for the patient with unstable angina before the cardiac operation can be risky. On the other hand, delay in improving

\section{$\ddot{O} Z$}

Atmış dokuz yaşında bir kadın hasta, ağır koroner arter hastalığına bağlı kararsız anjina ile kalp cerrahisi kliniğine başvurdu. Koroner arter baypas greftleme gerekli olmakla birlikte, hastanın daha önce pnömatik dilatasyon ile tedavi edilen akalazya semptomları kötüleşti. Akabinde hasta eş zamanlı cerrahiye alındı. Sternotomiden sonra kardiyopulmoner baypas sırasında özofagus açığa çıkarıldı ve Heller miyotomi yapıldı. Kardiyopleji sonrası koroner arter baypas greftleme gerçekleştirildi. Ameliyat sonrası süreç sorunsuz olup, hasta ameliyatın dokuzuncu gününde taburcu edildi. Sonuç olarak, bu yeni teknik, bu tür olgularda etkin bir şekilde kullanılabilir.

Anahtar sözcükler: Koroner arter baypas greftleme, özofageal akalazya, Heller miyotomi.

esophageal function after the cardiac intervention may create additional postoperative problems related to achalasia such as malnutrition, impaired fluid uptake, and aspiration..$^{[5]}$ One possibility is to perform both procedures simultaneously, but there is a lack of information about the simultaneous treatment of such cases. Previous studies have shown that simultaneous cardiac and non-cardiac operations have become more widespread, as they provide similar clinical outcomes compared to staged procedures and due to the costeffectiveness. However, it can only be done in carefully selected patients. ${ }^{[6-8]}$

In this article, we report the first case of simultaneous coronary artery disease (CAD) and

Received: March 10, 2021 Accepted: May 25, 2021 Published online: October 20, 2021

Correspondence: Algimantas Budrikis, MD. Department of Thoracic and Vascular Surgery, Lithuanian University of Health Sciences, Clinic of Cardiac, 50161 Kaunas, Lithuania. Tel: +37069889870 e-mail: budrikis@gmail.com 
achalasia surgery who successfully underwent simultaneous Heller myotomy and CABG via sternotomy.

\section{CASE REPORT}

A 69-year-old female patient with a known CAD and previously treated achalasia was hospitalized in the cardiac surgery department for a CABG procedure. The patient had a history of hypertension, hypertensive cardiomyopathy, CAD, and congestive heart failure. She was also diagnosed with third-degree atrioventricular block, acute myocardial infarction, and achalasia type II six months prior in an external center in abroad. At that time, the dual-chamber pacemaker was implanted, and the patient underwent percutaneous coronary intervention with stenting of the circumflex branch of the left coronary artery due to the "culprit lesion".

The patient returned to her country in a good condition; however, four months ago, achalasia symptoms aggravated. An achalasia diagnosis was confirmed in our hospital. Barium esophagography showed esophageal dilatation, delayed emptying, and the "bird beak" pattern (Figure 1). A contrastenhanced thoracic computed tomography (CT) revealed narrowing of gastroesophageal junction,

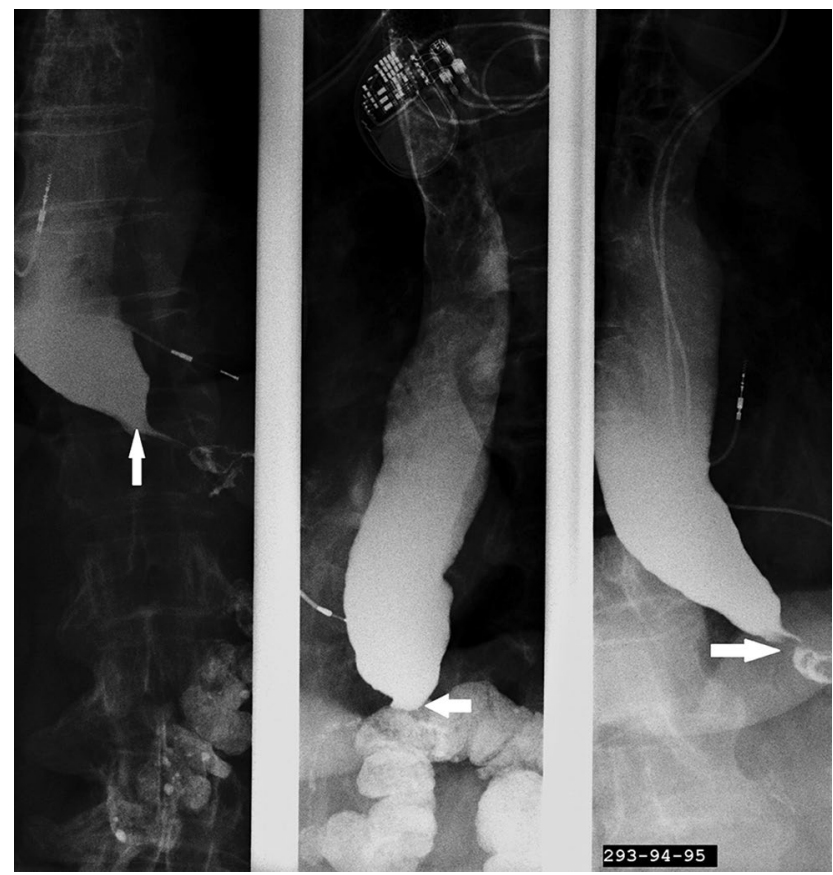

Figure 1. Barium esophagogram findings. The esophagus is dilated, delayed emptying and the "bird beak" pattern. The white arrow indicates the area of constriction. uniform dilatation of the esophagus, along with esophageal contents and residue of barium sulphate (Figure 2). Furthermore, endoscopic data did not rule out the diagnosis of achalasia, and there were no other specific findings. The gradual pneumatic dilatation was performed with a good initial effect. One month ago, angina symptoms were exacerbated, and coronary artery angiography was performed which showed advanced three-vessel disease with previously diagnosed right coronary artery (RCA) occlusion, stent restenosis in the circumflex branch of the left coronary artery, and significant stenosis in the proximal part of the left anterior descending coronary artery (LAD). The Heart Team recommended elective CABG. Meanwhile, the patient experienced previous dysphagia symptoms including the difficulty in swallowing, weight loss, vomiting after a meal, and regurgitation. The local medical team planned a repeat investigation for achalasia symptoms, but angina complaints aggravated. Once angina episodes became more frequent, even at rest, the patient was admitted for a CABG operation.

Upon arrival, the patient's vital signs and laboratory values were within normal limits. Angina episodes recurred during resting periods, although they were suppressed by nitrates. The electrocardiogram findings remained unchanged, and the troponin I remained within the normal limits. Echocardiography revealed that the left ventricular ejection fraction was

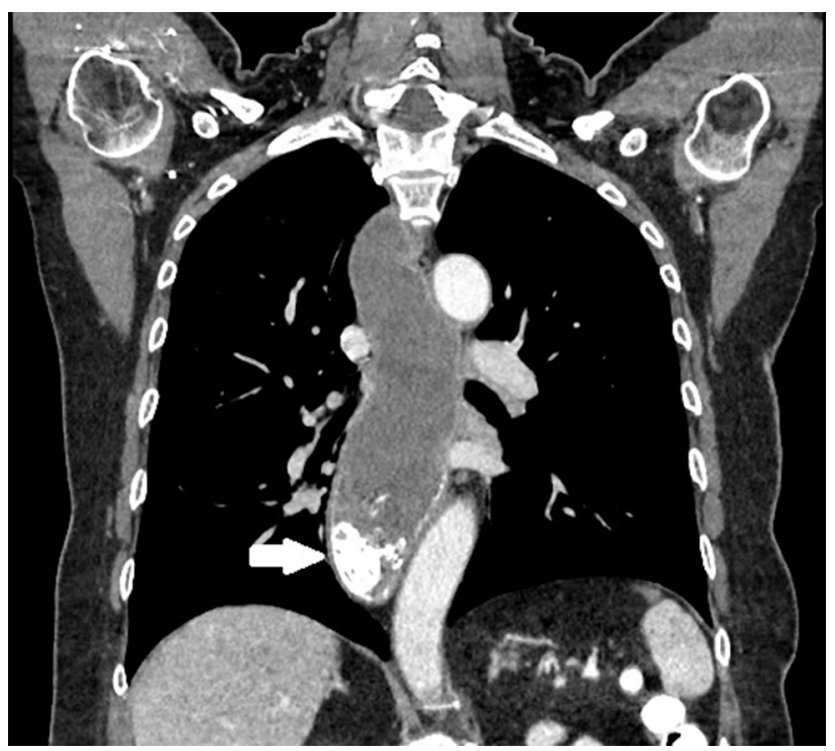

Figure 2. Contrast-enhanced thoracic computed tomography. Narrowing of gastroesophageal junction, uniform dilatation of esophagus along with esophageal contents and residue of barium sulphate (white arrow). 


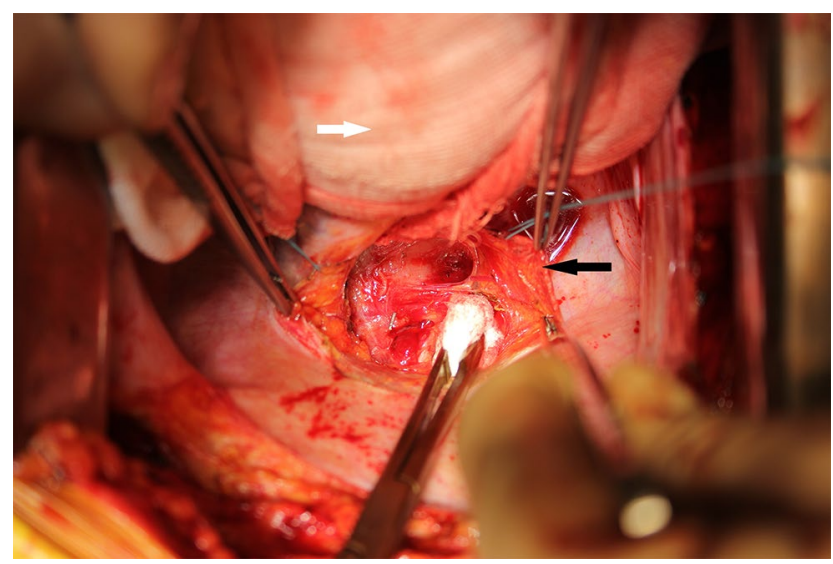

Figure 3. The apex of the heart lifted (white arrow). Dissection of esophageal muscular fibbers after incision of the posterior pericardium (black arrow).

slightly below normal, with no significant heart valve pathology. The multidisciplinary team decided to perform a simultaneous Heller myotomy and CABG via sternotomy. A written informed consent was obtained from the patient. In this case, our routine preoperative work-up was made. We used a 6-h fasting period, no drinks $4 \mathrm{~h}$ preoperatively, cefazoline prophylaxis, and nasogastric tube insertion.

After the initiation of anesthesia, a median sternotomy was performed. Left internal mammary artery (LIMA) and great saphenous vein were prepared. After heparinization and cannulation of the ascending aorta and right atrium, cardiopulmonary bypass was initiated. We obtained an optimal exposure to the esophagus's inferior part with an apex of the beating heart lifted. Following the incision of the posterior pericardium, the distal part of esophagus was exposed (Figure 3). A vertical myotomy with electrocautery was continued just above the gastroesophageal junction. The esophageal longitudinal and circular muscle fibers were gradually split and dissected laterally, preserving the anterior vagal trunk. The myotomy was performed approximately $2 \mathrm{~cm}$ below the gastroesophageal junction and $4 \mathrm{~cm}$ proximally of the esophagus. The integrity of the mucosa was checked by filling the wound with saline solution and injecting air through a nasogastric tube. No air leak was observed.

After the myotomy, we performed cardioplegia and CABG with LIMA-to-LAD and two venous grafts to RCA and circumflex arteries. Sinus rhythm recovered spontaneously at the reperfusion. The total duration of operation was $4 \mathrm{~h}$, and the total duration of cardiopulmonary bypass was $102 \mathrm{~min}$.
The postoperative period was uneventful. The patient was discharged to the rehabilitation clinic in a good condition on postoperative Day 9. The patient had no angina or achalasia symptoms for one-year follow-up after the operation.

\section{DISCUSSION}

The patient was admitted to the cardiac surgery clinic with multivessel CAD, unstable angina, and symptomatic achalasia. In this case, the most lifesaving strategy was to perform revascularization of the myocardium. However, possible problems with achalasia such as aspiration or malnutrition in the future could not be ignored. Different treatment tactics were discussed.

For patients with esophageal achalasia of type II, first-line therapy is usually pneumatic dilation for its high symptom relief rates, optimal costs, and a lower level of technical difficulty. Another treatment modality may be an injection of botulinum toxin which is a less invasive procedure, but it provides a lower degree of symptom relief and most of the patients require additional and more frequent injections. This type of treatment is usually reserved for older patients with acute comorbid diseases. If less invasive therapy options are proven unsuccessful, the treatment should be continued with Heller myotomy, which has also a high percentage of success ${ }^{[3]}$ Recent studies have shown that the new method - POEM provides greater short-term follow-up efficacy than Heller myotomy. ${ }^{[9]}$ Nevertheless, the number of data regarding its long-term efficacy is still limited. ${ }^{[4]}$

In our case, coronary artery angiography showed advanced three-vessel disease with RCA occlusion, stent restenosis in the circumflex branch of the left coronary artery, and significant stenosis in the proximal part of the LAD. In such cases, the CABG procedure is the most appropriate method of treatment. The revascularization of coronary arteries cannot be delayed due to angina aggravation. Achalasia treatment is indicated due to malnutrition and aspiration risk after cardiac operation. ${ }^{[5]}$ In our case, the multidisciplinary team decided to perform simultaneous Heller myotomy and CABG, as there was a possibility to eliminate angina and achalasia symptoms at the same time. We chose myotomy, since gradual pneumatic dilation failed previously. Moreover, the lower part of the esophagus could be easily accessed during CABG surgery. The patient was also informed of the potential risks and benefits of different treatment methods. To illustrate, the simultaneous approach has a higher risk of infection and hemorrhage, 
while the staged approach is associated with a longer postoperative care, requirement of second intervention, higher risk of malnutrition, impaired fluid uptake, and risk of aspiration following CABG. Based on the preference of the patient, simultaneous surgery was planned.

In the literature, there is no such a procedure described, although there are similar operations reported. Combined cardiac and non-cardiac operations are feasible in selected patients and can provide tolerable, long-term and short-term outcomes. In a study, Zhang et al. ${ }^{[6]}$ compared simultaneous CABG and esophagectomy versus single esophagectomy. The length of stay in hospital was longer in the first group, but postoperative complications and overall survival were not significant between the groups. In another study, Liu et al. ${ }^{[7]}$ showed that the combined procedure of off-pump CABG and esophagectomy for patients with severe CAD and esophageal cancer was a safe and effective treatment option. However, the authors described difficult access for LIMA harvesting.

In our case, only Heller myotomy was done without fundoplication. It has been shown that fundoplication after myotomy prevents gastroesophageal reflux (GER). ${ }^{[10]}$ On the other hand, Bagheri et al. ${ }^{[1]}$ revealed the positive aspects of the transthoracic approach and noted that GER symptoms were less present in the transthoracic group, compared to the transabdominal group, regardless whether the antireflux procedure was done or not. Moreover, robotic Heller myotomy without fundoplication showed excellent results. ${ }^{[12]}$ We also suggest that there is the possibility to do fundoplication later, if drugresistant GER appears that is rarely used in case of GER appearance after POEM. ${ }^{[13]}$

Nevertheless, the limitation of this method is that Heller myotomy was done on cardiopulmonary bypass under full systemic heparinization. There is an increased risk of bleeding during esophageal exposure and myotomy. We used on-pump CABG, as we thought it would be easier to expose the esophagus, LIMA, and coronary arteries simultaneously. On the other hand, we believe that off-pump CABG can be used for this simultaneous procedure.

In conclusion, we believe that this novel surgical technique, that is the first report in the literature, can be used in cardiac surgery patients in whom interventions due to symptomatic achalasia are indicated.

\section{Declaration of conflicting interests}

The authors declared no conflicts of interest with respect to the authorship and/or publication of this article.

\section{Funding}

The authors received no financial support for the research and/or authorship of this article.

\section{REFERENCES}

1. Neumann FJ, Sousa-Uva M, Ahlsson A, Alfonso F, Banning AP, Benedetto U, et al. 2018 ESC/EACTS Guidelines on myocardial revascularization. Eur Heart J 2019;40:87-165.

2. Kusu-Orkar, T-E, Kermali, M, Oguamanam, N, Bithas, C, Harky, A. Coronary artery bypass Grafting: factors affecting outcomes. J Card Surg 2020;35:3503-11.

3. Schlottmann F, Patti MG. Esophageal achalasia: Current diagnosis and treatment. Expert Rev Gastroenterol Hepatol 2018;12:711-21.

4. Werner YB, Costamagna G, Swanström LL, von Renteln D, Familiari P, Sharata AM, et al. Clinical response to peroral endoscopic myotomy in patients with idiopathic achalasia at a minimum follow-up of 2 years. Gut 2016;65:899-906.

5. Unosawa S, Taoka M, Osaka S, Yuji D, Kitazumi Y, Suzuki K, et al. Is malnutrition associated with postoperative complications after cardiac surgery? J Card Surg 2019;34:908-12.

6. Zhang W, Liu B, Zhou Y, Wang F, Gu C, Wang Q, et al. Combined surgical treatment of esophageal cancer and coronary heart diseases in elderly patients. World J Surg Oncol 2018;16:213.

7. Liu B, Gu C, Wang Y, Wang X, Ge W, Shan L, et al. Feasibility and efficacy of simultaneous off-pump coronary artery bypass grafting and esophagectomy in elderly patients. Oncotarget 2017;8:46498-505.

8. Civelek A, Ak K, İsbir CS, Yeğen C, Arsan S. Simultaneous gastrectomy and off-pump coronary artery bypass grafting: A case report. Turkish J Thorac Cardiovasc Surg 2011;19:642-4.

9. Chan SM, Wu JCY, Teoh AYB, Yip HC, Ng EKW, Lau JYW, et al. Comparison of early outcomes and quality of life after laparoscopic Heller's cardiomyotomy to peroral endoscopic myotomy for treatment of achalasia. Dig Endosc 2016;28:27-32.

10. Di Corpo M, Farrell TM, Patti MG. Laparoscopic heller myotomy: A fundoplication is necessary to control gastroesophageal reflux. J Laparoendosc Adv Surg Tech A 2019;29:721-5.

11. Bagheri R, Haghi SZ, Noorshafiee S. Surgical treatment of achalasia: Transabdominal versus transthoracic cardiomyotomy. Ann Thorac Cardiovasc Surg 2011;17:254-9.

12. Gharagozloo F, Atituzzman N, Atiquzzman B. Robotic lateral heller myotomy without fundoplication for achalasia. Mini-invasive Surg 2020;4:22.

13. Inoue H, Shiwaku H, Kobayashi Y, Chiu PWY, Hawes RH, Neuhaus H, et al. Statement for gastroesophageal reflux disease after peroral endoscopic myotomy from an international multicenter experience. Esophagus 2020;17:3-10. 